\title{
Faktor-Faktor yang Mempengaruhi Implementasi Program Kebun Bibit Rakyat (KBR)
}

(Factors Effecting the Implementation of the Community Nursery Program $(K B R)$ )

\author{
Warhamna $^{1}$, Martunis ${ }^{1 *}$, Ryan Moulana ${ }^{1}$ \\ 1Program Studi Kehutanan PSDKU Unsyiah Gayo Lues \\ Universitas Syiah Kuala \\ *Corresponding author: raja_acehrayeuk@yahoo.de
}

\begin{abstract}
Abstrak. Program Kebun Bibit Rakyat (KBR) merupakan salah satu program Rehabilitasi Hutan dan Lahan (RHL) yang berbasis swakelola masyarakat dan bertujuan untuk menyediakan bibit berkualitas baik sehingga diharapkan dapat meningkatkan minat tanam masyarakat. Upaya untuk merehabilitasi hutan dan lahan akan berjalan apabila masyarakat dapat berpartisipasi dalam program tersebut. Desa Beutong dan Desa Ujong Mangki merupakan desa yang mengikuti program KBR. Penelitian ini bertujuan untuk mengetahui faktor-faktor apa saja yang mempengaruhi tingkat partisipasi masyarakat dalam program KBR. metode yang digunakan adalah dengan cara menganalisis data kuantitatif menggunakan perangkat Statisctical Program from Social Science (SPSS) 22 dan Microsoft Exel 2007. Untuk melihat hubungan antar variabel maka data diolah menggunakan uji korelasi Rank Spearman. Hasilnya menunjukkan bahwa pada Desa Beutong, korelasi antara faktor umur, pendidikan, pendapatan, jumlah tanggungan keluarga tidak berkorelasi terhadap keikutsertaan seseorang pada program KBR. Pada Desa Ujong Mangki, faktor umur dan pendapatan berkorelasi signifikan sedangkan faktor pendidikan dan jumlah tanggungan keluarga tidak berkorelasi terhadap keikutsertaan masyarakat pada program KBR.
\end{abstract}

Kata Kunci: Program KBR, Faktor internal, Partisipasi Masyarakat

Abstract. The People's Seed Garden Program (KBR) is one of the community-based Forest and Land Rehabilitation (RHL) programs and aims to provide good quality seeds that are expected to increase community planting interest. Efforts to rehabilitate forests and land will proceed if the community can participate in the program. Beutong Village and Ujong Mangki Village are villages that participated in the KBR program. This study aims to determine what factors influence the level of comunity participation in the KBR program. Data analysis conducted was quantitative data analysis supported by qualitative data. Quantitative data were analyzed using Statistical Software Program from Social Science (SPSS) 22 and Microsoft Excel 2007. To see the relationship between variables, the data is processed using the Spearman Rank correlation test. The result show that in Beutong Village, the correlation between factors of age, education, income, and number of family dependents does not correlate for one's participation in the KBR program. In Ujong Mangki Village, age and income were significantly correlated, while education and number of family dependents does not have a correlation with community participation in the KBR program.

Keywords: KBR Program, Internal Factors, Community Participation 


\section{PENDAHULUAN}

Salah satu negara yang memiliki hutan terbesar di dunia adalah hutan yang terdapat di Indonesia. Indonesia telah mengatur dan melindungi berbagai macam fungsi dan pemanfaatan hutan dalam Undang-Undang Kehutanan. Pemanfaatan hutan di Indonesia tentu saja selain untuk menyejahterakan rakyat juga demi melestarikan lingkungan. Namun dari berbagai peristiwa yang terjadi seperti illegal logging (pembalakan liar), kebakaran hutan serta pemanfaatan hutan yang tidak tepat membuat jumlah kawasan hutan di Indonesia semakin menyempit dan terjadinya kerusakan yang semakin luas sehingga mengganggu fungsi hutan itu sendiri.

Program Kebun Bibit Rakyat (KBR) merupakan salah satu progra pemerintah yang ditujukan untuk terus meningkatkan capaian rehabilitasi hutan dan lahan yang merupakan fasilitasi pemerintah dalam penyediaan bibit tanaman hutan maupun tanaman serbaguna (MPTS) yang prosesnya dibuat secara swakelola oleh kelompok tani (Permenhut no 17 tahun 2012).

Kabupaten Aceh Selatan merupakan salah satu kabupaten yang telah menjalankan program KBR sejak tahun 2017. Program ini tersebar di beberapa desa kecamatan dengan melibatkan masyarakat setempat secara langsung sebagai kelompok pengelola KBR. Partisipasi masyarakat dalam program kegiatan KBR sangat berpengaruh dalam keberhasilan pelaksanaan kegiatan program itu sendiri. Partisipasi ini bisa dikatagorikan ke dalam berbgai aspek yakni aspek ekonomi, ekologi, dan aspek sosial yang tergolong ke dalam faktor internal dan eksternal. Untuk mengetahui faktor penyebab masyarakat dapat berpartisipasi pada program KBR yang terjadi pada 2 desa yaitu Desa Beutong Kecamatan Kota Bahagia dan Desa Ujong Mangki Kecamatan Bakongan yang terdapat di Kabupaten Aceh Selatan maka perlu dilakukan penelitian untuk menjawab permasalahan tersebut.

\section{METODE PENELITIAN}

\section{Tempat dan Waktu Penelitian}

Penelitian dilakukan di Desa Beutong Kecamatan Kota Bahagia dan Desa Ujong Mangki Kecamatan Bakongan, Kabupaten Aceh Selatan. Penelitian berlangsung pada bulan November 2019 di lapangan untuk memperoleh data primer dan sekunder.

\section{Alat dan Bahan}

Alat yang dipergunakan pada saat melakukan penelitian ialah komponen laptop, alat tulis, kamera atau handphone untuk pengambilan dokumentasi, serta alat perekam suara. Sedangkan bahan yang dipergunakan ialah kuesioner yang berfungsi sebagai pedoman pada saat melakukan wawancara pada responden pada saat pengumpulan data langsung di lapangan.

\section{Populasi dan Sampel}

Jumlah populasi yang akan diobservasi yaitu sebanyak 307 KK (Kepala Keluarga) dari 2 desa yaitu 70 KK Desa Beutong dan 237 KK dari Desa Ujong Mangki. Sampel yang 
akan diambil sebanyak 13\% sehingga jumlah responden sebanyak $40 \mathrm{KK}$ yang merupakan masyarakat yang terlibat dalam program KBR. Jika subjek dalam penelitian $\leq 100$ seharusnya diteliti seluruh sampel atau disebut dengan penelitian populasi, namun jika populasi lebih besar dari 100, maka penelitian sampel diambil sebanyak 10\%-30\% dari populasi tersebut (Latjompo, 2013).

Objek penelitian yang dilaksanakan di setiap desa yaitu :

- Masyarakat biasa : 8 orang/desa

- Tokoh desa : 2 orang/desa

- Kelompok tani KBR : 10 orang/desa

\section{Analisis Data}

Teknik yang akan dikerjakan untuk menganalisis data ialah dengan menggunakan data Kuantitatif berserta data kualitatif yang sudah didapatkan. Perangkat yang digunakan untuk menganalisis data kuantitatif adalah Statistical Program from Social Science (SPSS) 22 juga perangkat Microsoft Exel 2007. Kemudian digunakan uji korelasi Rank Spearman untuk mengukur signifikansi antar variabel yang berskala ordinal (nonparametrik), yaitu:

\section{a. Skala Likert}

Penilaian variabel yakni faktor internal dan faktor eksternal di atas menggunakan bantuan skoring yang dilakukan dengan sistem penilaian 'Skala Likert" dengan indeks skor jenjang empat " $4,3,2,1$ " secara berurutan. Kemudian skor di rubah dalam bentuk skala. Skala ditentukan intervalnya terlebih dahulu dengan rumus :

$$
\text { Interval }=\frac{\text { Bobot nilai tertinggi-Bobot nilai terendah }}{\text { Banyaknya kelas }}
$$

\section{b. Uji Korelasi Rank Spearman}

Untuk memeriksa signifikansi hubungan, kekuatan hubungan, serta memeriksa arah hubungan antar variabel digunakan Rumus Rank Spearman sebagai berikut:

$$
\mathrm{rs}=1-\frac{6 \sum d^{2}}{n\left(n^{2}-1\right)}
$$


Keterangan :

rs = Koefisien Korelasi Rank Spearman

$\mathrm{d}^{2}=$ Selisih Peringkat $\mathrm{x}$ dan $\mathrm{y}(\mathrm{x}-\mathrm{y})$, dimana

$\mathrm{x}=$ Umur, pendidikan, jumlah tanggungan keluarga, pendapatan

$\mathrm{y}=$ Partisipasi masyarakat

$\mathrm{n}=$ Jumlah sampel penelitian

Tabel 1. Panduan Interpretasi tingkat koefisien korelasi

\begin{tabular}{cc}
\hline Interval Koefisien & Tingkat Hubungan \\
\hline $0,00-0,19$ & Sangat Rendah \\
$0,20-0,39$ & Rendah \\
$0,40-0,59$ & Sedang \\
$0,60-0,79$ & Kuat \\
$0,80-1,00$ & Sangat Kuat \\
\hline
\end{tabular}

Sumber: Sugiyono (2013:250).

Untuk pengujian signifikan dalam SPSS digunakan kriteria sebagai berikut:

- Jika signifikan hasil riset $<0,05$ maka hubungan kedua variabel signifikan

- Jika signifikan hasil riset >0,05 maka hubungan kedua variabel tidak signifikan.

\section{HASIL DAN PEMBAHASAN}

\section{Partisipasi Masyarakat dalam program KBR}

Keikutsertaan yang rendah berpengaruh negatif dan akan menghambat pelaksanaan program KBR, sebaliknya partisipasi yang tinggi berpengaruh positif dan merupakan suatu hal yang diharapkan oleh pemerintah sebagai dukungan dalam menunjang pencapaian keberhasilan program tersebut. Adapun frekuensi jawaban masyarakat terhadap partisipasi dalam program KBR ini berdasarkan hasil wawancara langsung dapat dilihat pada Gambar 1 . 


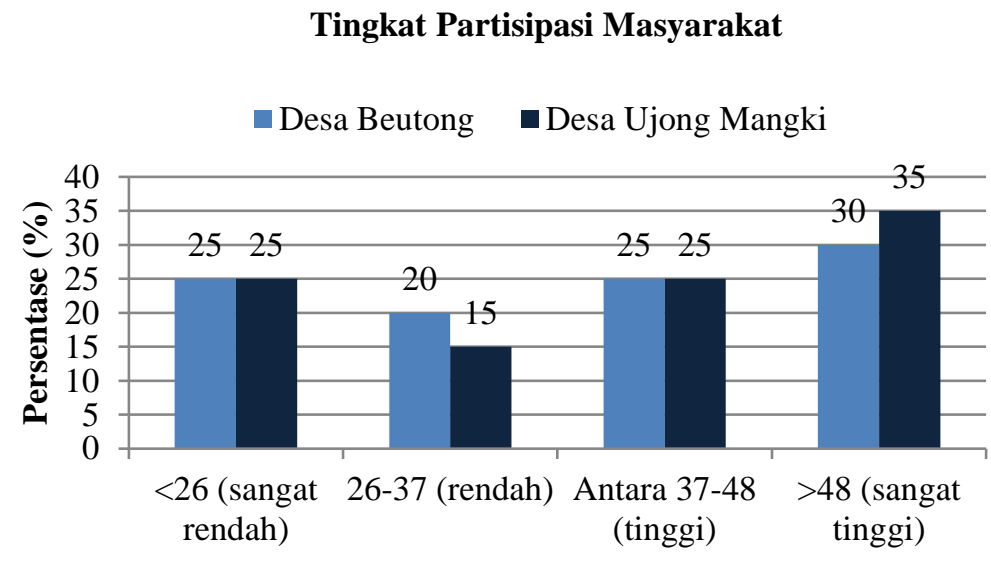

Skor Jawaban Responden

Gambar 1. Persentase Skor Jawaban Tingkat Partisipasi Masyarakat Responden

Peristiwa tersebut ibarat penyelidikan yang dilaksanakan Rahmawati juga sumarti tahun 2011 tentang keikutsertaan anggota kegiatan CSR fase keinginan anggota kegiatan pemberdayaan ekonomi lebih banyak dan anggota menaruh harapan besar kepada program tersebut.

\section{Faktor-Faktor yang Mempengaruhi Partisipasi Masyarakat}

Terdapat berbagai faktor yang dapat mempengaruhi partisipasi masyarakat ke dalam program KBR yaitu faktor umur, faktor pendidikan, faktor pendapatan, faktor jumlah tanggungan keluarga. Untk melihat faktor tersebut maka dilakukan analisis Rank Spearman sehingga dapat diperoleh hasil pada Tabel 2.

Tabel 2. Hasil analisis Rank Spearman Desa Beutong dan Desa Ujong Mangki

\begin{tabular}{lcccc}
\hline \multirow{2}{*}{ Faktor Internal } & \multicolumn{2}{c}{ Desa Beutong } & \multicolumn{2}{c}{ Desa Ujong Mangki } \\
\cline { 2 - 5 } & Koefisien korelasi & Sig & Koefisien korelasi & Sig \\
\hline Umur & 0,119 & 0,617 & 0,616 & 0,004 \\
Pendidikan & $-0,211$ & 0,371 & 0,252 & 0,285 \\
Pendapatan & 0,025 & 0,971 & 0,430 & 0,050 \\
Tanggungan keluarga & 0,215 & 0,363 & $-0,167$ & 0,482 \\
\hline
\end{tabular}

\section{Hubungan faktor umur terhadap partisipasi masyarakat pada program KBR}

Bersumber dari analisis Rak Spearman membuktikan bahwasanya koefisien hubungan faktor umur terhadap partisipasi seseorang di Desa Beutong adalah 0,119 dan nilai signifikan (2-tailed) adalah 0,617. Hal ini menunjukkan bahwa umur memiliki tingkat hubungan sangat rendah untuk desa ini dan berkorelasi tidak signifikan dengan partisipasi masyarakat (Dolisca dkk, 2006). Oleh sebab itu kelompok umur produktif maupun kurang produktif bisa saja mengikuti program KBR. 
Koefisien korelasi antara faktor umur dengan partisipasi masyarakat Desa Ujong Mangki adalah $0,616^{* *}$ dan nilai signifikan (2-tailed) yaitu 0,004. Kondisi ini memperlihatkan bahwasanya umur memiliki tingkat korelasi yang kuat dan berkorelasi signifikan dengan partisipasi masyarakat dalam program KBR. Berdasarkan survei di lapangan umur yang lebih muda atau produktif lebih banyak ikut berpartisipasi dalam program KBR di Desa tersebut. Umur produktif merupakan usia ideal dan masih kuat untuk melakukan kegiatan-kegiatan. Pada hakikatnya umur berpengaruh pada efektifitas kerja, terutama dalam hal pembibitan yang harus melakukan pekerjaan yang berat. Oleh sebab itu umur mempengaruhi partisipasi masyarakat dalam program KBR Desa Ujong Mangki.

Faktor umur dengan partisipasi masyarakat dalam program KBR pada kedua desa memiliki korelasi yang berbeda yakni Desa Beutong berkorelasi tidak signifikan sedangkan Desa Ujong Mangki berkorelasi signifikan. Berdasarkan data penduduk Desa Beutong memiliki jumlah penduduk lebih sedikit dibandingkan dengan Desa Ujong Mangki sehingga umur (produktif/kurang produktif) bisa saja ikut berpartisipasi dalam mengikuti program KBR di Desa tersebut. Berbeda halnya dengan Desa Ujong Mangki yang memiliki jumlah penduduk yang lebih banyak, mereka lebih mengutamakan kelompok umur produktif untuk berpartisipasi.

\section{Hubungan Antara Faktor Pendidikan dengan Partisipasi Masyarakat dalam Program KBR}

Bersumber pada analisis Rank Spearman memperlihatkan koefisien korelasi faktor pendidikan terhadap partisipasi warga Desa Beutong adalah -0,211 dan nilai signifikan (2tailed) adalah 0,371. Hal ini menunjukkan bahwa pendidikan memiliki tingkat hubungan lemah dan berkorelasi tidak signifikan dengan partisipasi masyarakat dalam program KBR. Walaupun pendidikan SMA lebih dominan mengikuti program, tetapi terdapat juga masyarakat yang hanya berpendidikan SD dan SMP yang ikut serta dalam program. Oleh sebab itu pendidikan sama sekali tidak dijadikan acuan dalam partisipasi seseorang untuk mengikuti program KBR di Desa Beutong.

Koefisien korelasi antara faktor pendidikan dengan partisipasi masyarakat Desa Ujong Mangki memiliki kekuatan hubungan sebesar 0,252 dan nilai signifikan (2-tailed) yaitu 0,282. Keadaan tersebut memperlihatkan pendidikan memiliki tingkat hubungan yang rendah dan berkorelasi tidak signifikan dengan partisipasi masyarakat dalam program KBR. Berdasarkan survei di lapangan pendidikan tidak menentukan seseorang untuk berpartisipasi pada program KBR. Pada dasarnya pendidikan merupakan faktor yang penting untuk melihat kemampuan dan pola pikir seseorang seperti yang dikemukakan oleh Y. Slamet (2004) bahwa tingginya pendidikan seseorang akan memperoleh ilmu yang lebih besar mengenai pengembangan serta peran yang diberikan. Dalam lingkup KBR masyarakat yang berpartisipasi memiliki kemauan sendiri dan pengalaman yang dimiliki terutama dalam bidang pertanian seperti petani yang rata-rata tidak mengenyam pendidikan formal. Seseorang yang lebih berpengalaman lebih besar partisipasi yang lebih tinggi 
dibanding yang lain sebab orang yang berkompeten lebih mempunyai kapasitas serta keahlian.

\section{Hubungan antara Pendapatan terhadap Partisipasi Masyarakat pada Program KBR}

Berlandaskan dari hasil analisis Rank Spearman menyatakan bahwasanya koefisien korelasi faktor pendapatan terhadap partisipasi warga Desa Beutong adalah 0,025 dan nilai signifikan (2-tailed) yaitu 0,917. Keadaan tersebut memperlihatkan tingkat pendapatan mempunyai korelasi rendah juga berkorelasi tidak signifikan dengan partisipasi masyarakat dalam program KBR. Berdasarkan survei di lapangan masyarakat yang berpartisipasi dalam program bisa saja berpendapatan tinggi maupun rendah karena keikutsertaan seseorang dalam program hanya di pengaruhi oleh kemauan dan waktu luang yang dimiliki dari profesi utama yang dilakukan. Rata-rata masyarakat tidak menggantungkan pendapatannya pada program KBR, biasanya mereka lebih fokus pada kegiatan pertanian seperti berkebun sebagai pendapatan utama, sehingga berkurangnya waktu yang diluangkan untuk mengikuti program tersebut. Hal ini sama dengan pendapat Budiharjo dan Sujarto (2009) yang menyatakan bahwa waktu senggang orang agar berpartisipasi pada suatu organisasi dan aktivitas yang dapat diakibatkan oleh tipe pekerjaan yang dilakukan, banyak orang yang sudah terlalu sibuk dengan profesinya seharian sehingga susah untuk mengikuti musyawarah.

Koefisien korelasi antara faktor pendapatan dengan partisipasi masyarakat Desa Ujong Mangki memiliki kekuatan hubungan sebesar $0,430^{*}$ dan nilai signifikan (2-tailed) adalah 0,050. Hal ini menunjukkan bahwa pendapatan memiliki tingkat hubungan sedang dan berkorelasi signifikan dengan partisipasi masyarakat dalam program KBR. Menurut hasil survei di lapangan yang ikut dalam program KBR rata-rata lebih banyak dari tingkat pendapatan yang rendah dibandingkan dengan pendapatan yang tinggi. Apabila pekerjaan utama sebagai nelayan tidak dapat dilakukan akibat faktor alam atau lainnya, maka kegiatan KBR ini dapat dilakukan saat memiliki waktu atau hanya untuk selingan saja. Biasanya orang yang berpendapatan tinggi memiliki kesibukannya sendiri sehingga tidak memiliki waktu luang untuk mengikuti program masyarakat seperti program KBR. Oleh sebab itu tingkat pendapatan seseorang berpengaruh terhadap partisipasi seseorang dalam program KBR di Desa Ujong Mangki.

\section{Hubungan Antara Faktor Jumlah Tanggungan Keluarga dengan Partisipasi Masyarakat dalam Program KBR}

Berdasarkan hasil uji analisis Rank Spearman menyatakan bahwasanya koefisien hubungan faktor beban tanggungan keluarga terhadap partisipasi warga Desa Beutong adalah 0,215 dan nilai signifikan (2-tailed) adalah 0,363. Hal ini menunjukkan bahwa jumlah tanggungan keluarga memiliki tingkat hubungan rendah dan berkorelasi tidak signifikan dengan partisipasi masyarakat dalam program KBR. Hal ini berarti berapapun jumlah tanggungan keluarga tidak ada hubungannya dengan partisipasi responden dalam mengikuti program KBR, karena keputusan untuk berpartisipasi ditentukan oleh masyarakat itu sendiri seperti menghadiri pertemuan dan mengikuti tahapan kegiatan seperti persiapan lahan, persemaian, perawatan hingga penanaman. Hal serupa juga terjadi pada Desa Ujong Mangki bahwa koefisien korelasi antara jumlah tanggungan keluarga 
dengan partisipasi masyarakat Desa Ujong Mangki memiliki kekuatan hubungan sebesar 0,167 dan nilai signifikan (2-tailed) adalah 0,482. Hal ini menunjukkan bahwa jumlah tanggungan keluarga memiliki tingkat hubungan lemah dan berkorelasi tidak signifikan dengan partisipasi masyarakat dalam program KBR Ujong Mangki. Namun kondisi ini berbeda dengan pernyataan Sihol Situngkir (2007) yang menyatakan bahwa peluang yang diberikan seseorang agar bekerja secara efisien dipengaruhi dengan banyaknya jumlah tanggungan/anak.

Faktor jumlah tanggungan keluarga baik Desa Beutong maupun Desa Ujong Mangki sama-sama tidak berkorelasi dengan partisipasi masyarakat dalam program KBR. Seharusnya jika total beban dalam satu keluarga lebih besar maka semakin banyak keperluan yang mesti disanggupi dengan menambah pekerjaan. Namun berdasarkan hasil survei di lapangan masyarakat Desa Beutong lebih mengacu dalam sektor pertanian seperti perkebunan sawit dan menanam padi sedangkan Desa Ujong Mangki lebih mengacu sebagai nelayan dibandingkan dengan program KBR yang tidak memperoleh pendapatan yang pasti dan tidak dapat menjamin masyarakat untuk memperoleh pendapatan setiap bulannya. Oleh sebab itu program ini hanya diikuti untuk selingan sebagai tambahan saja.

\section{KESIMPULAN DAN SARAN}

\section{Kesimpulan}

1. Berdasarkan uji korelasi Rank Spearman, pada Desa Beutong yakni faktor umur, pendidikan, pendapatan, jumlah tanggunagan keluarga berkorelasi tidak signifikan terhadap leikutsertaan masyarakat pada program KBR.

2. Berdasarkan uji korelasi Rank Spearman, pada Desa Ujong Mangki faktor umur dan pendapatan berkorelasi signifikan sedangkan faktor pendidikan serta tanggungan keluarga berkorelasi tidak signifikan terhadap keikutsertaan masyarakat pada program KBR.

\section{Saran}

Berdasarkan hasil penelitian faktor internal tidak terlalu berpengaruh terhadap partisipasi masyarakat dalam program KBR. Oleh sebab itu, sebaiknya pihak penyelanggara lebih memaksimalkan pengelolaan bibit secara baik agar menghasilkan bibit berkualiatas dan tentnya mencapai target yang diharapkan. Selain itu juga pemerintah harus melakukan survei yang lebih mendalam mengenai pemilihan jenis tumbuhan yang sesuai dengan minat masyarakat atau memberi akses pasar yang menjanjikan. 


\section{DAFTAR PUSTAKA}

Budiharjo, E., dan Sujarto, E. 2009. Kota Berkelanjutan. Bandung. Penerbit Alumni.

Dolisca, F., D.R. Carter, J.M. Daniel, D. A. Shannon, dan C. M. Jolly. 2006. Faktors Influencing Farmer's Participation in Forestry Management Programs. Forest cology and Management.

Latjompo, J. 2013. Partisipasi Masyarakat terhadap Rehabilitasi hutan dan Lahan di Desa Pembewe Kecamatan Sigi Biromaru Kabupaten Sigi. Palu. Fakultas Kehutanan UNTAD.

Menteri Kehutanan. 2012. Pedoman Teknis Kebun Bibit Rakyat. Jakarta. Peraturan Menteri Kehutanan Peraturan 17/Menhut/2012.

Puspitawati, E. 2004. Analisis Kemitraan antar PT Petani Persero dengan Petani Penangkar Benih Padi di Kabupaten Kerawang. Bogor. Program Pascasarjana IPB.

Rahmawati, dan Sumarti, T. 2011. Analisis Tingkat Partisipasi Peserta Program CSR Pemberdayaan Ekonomi PT Arutmin Indonesia. Jurnal Disiplin Ekologi Manusia, Sosiologi, dan Komunikasi.

Slamet, Y. 2004. Pembangunan Masyarakat Berwawasan Pertisipasi. Sukarta. University Press.

Situngkir, Sihol, Lubis Pulina dan Erida. 2007. Peranan Ibu Rumah Tangga dalam Meningkatkan Pendapatan Keluarga (Kasus Pedagang sayur di Kota Madya Jambi). Jurnal Management dan Pembangunan.

Sigoyono. 2013. Metode Penelitian Pendidikan Pendekatan Kuantitatif, Kualitatif, dan $R \& D$. Bandung. 